\title{
MAPEAMENTO DO CRIME E ANÁLISE CRIMINAL: A EXPERIÊNCIA DO ESTADO DO PARANÁ
} CRIME MAPPING AND CRIME ANALYSIS: THE STATE PARANÁ EXPERIENCE

\section{Marcelo Bordin}

Geógrafo, Mestre em Geografia (UFPR), Cientista Político (FACINTER), Especialista em Sociologia Política (UFPR) e Saúde Pública (IBPEX), Pesquisador do Centro de Estudos em Segurança Pública e Direitos Humanos da UFPR, Soldado da Polícia Militar do Paraná e Analista Criminal da Coordenadoria de Análise e Planejamento Estratégico da Secretaria de Estado da Segurança Pública do Paraná.

e-mail: marcelobordin@hotmail.com

Rodrigo Perim de Lima

Bacharel em Direito (UNIBRASIL), Especialista em Polícia Judiciária Militar (PMPR), Pós-Graduando em Gestão de Pessoas pela Universidade Araucária, Analista Criminal da Coordenadoria de Análise e Planejamento Estratégico da Secretaria de Estado da Segurança Pública do Paraná, Capitão da Polícia Militar do Paraná e Chefe da Seção de Instrução da $3^{a}$ Seção do Estado Maior da Polícia Militar do Paraná.

e-mail: perim_23@hotmail.com 


\section{Resumo}

O Brasil tem apresentado nas últimas três décadas alarmantes índices de violência e criminalidade, especialmente nas capitais e suas regiões metropolitanas. Com base nesse aspecto, alguns governos estaduais buscaram implementar políticas públicas no sentido de gerenciar e melhor aplicar os recursos destinados à segurança pública de forma racional e com mais efetividade. O Estado do Paraná buscou implementar a partir do ano de 2003 um programa de acompanhamento e mapeamento da criminalidade por meio da análise criminal, promovendo o mapeamento das ocorrências policiais com a utilização de um boletim unificado de ocorrências, colocando fim à duplicidade dos registros das polícias civis e militares. Este trabalho pretende verificar os avanços e as dificuldades encontradas para a sistematização e implementação de um sistema de acompanhamento das ocorrências policiais registradas e, consequentemente, o uso da análise criminal como ferramenta de gestão do trabalho policial, sejam eles operacionais, táticos ou estratégicos.

Palavras-chave: mapeamento criminal; análise criminal; geoprocessamento policial.

\section{Abstract}

Brazil also has three decades alarming levels of violence and crime, especially in capital cities and their metropolitan regions. Based on this aspect, some state governments sought to implement public policies toward managing and better apply the resources allocated to public safety in a rational and more effectively. The Paraná State sought to implement from the year 2003 a program of monitoring and mapping of crime through crime analysis, mapping of events promoting the police report through a unified events, ending duplication of records of civilian police and military . This paper aims to check the progress and difficulties encountered in the systematization and implementation of a monitoring system of police incidents recorded and therefore the use of crime analysis as a management tool of police work, whether operational, tactical or strategic.

Keywords: crime mapping; crime analysis; police GIS. 


\section{Resumen}

Brasil ha hecho en los últimos tres décadas, las tasas alarmantes de la violencia y la delincuencia, especialmente en las ciudades capitales y sus regiones metropolitanas. Con base en este aspecto, algunos gobiernos estatales tratado de aplicar las políticas con el fin de mejorar la gestión y aplicar los recursos para la seguridad pública de manera racional y eficaz. El Estado de Paraná trató de aplicar a partir del año 2003, un programa para el monitoreo y mapeo de la delincuencia a través del análisis del crimen, la cartografía de la promoción de los informes policiales con el uso de un boletín de noticias unificada de los acontecimientos, poniendo fin a la duplicidad de los registros de la policía civiles y militares. Este trabajo tiene la intención de verificar los avances y dificultades encontradas en la sistematización e implementación de un sistema de seguimiento de los incidentes registrados la policía y por lo tanto el uso de análisis de la delincuencia como una herramienta de gestión en la labor policial, ya sea operativo, táctico o estratégico.

Palabras clave: mapeo de la delincuencia; el análisis de la delincuencia; director de SIG. 


\section{Introdução}

A sociedade brasileira tem enfrentado nas três últimas décadas níveis alarmantes de violência urbana ${ }^{1}$, seja na forma de homicídios, roubos, furtos, seja no cotidiano do trânsito caótico das grandes cidades. O processo de urbanização por demasiado acelerado e com falta de políticas públicas efetivas, não apenas no que diz respeito ao consumo de bens não duráveis, mas também de acesso à educação, à moradia e a melhores condições de saúde, contribui para que as cidades pareçam mais inseguras.

Esse processo ainda contribui para a criação de áreas segregadas, muitas vezes formadas pela vontade própria de seus moradores, habitando mais condomínios que hoje

1 Não entraremos na discussão sobre a violência nas áreas rurais, que também é considerada altíssima, pois possui características outras que não é objeto de discussão deste trabalho (para os casos de violência e violação de direitos das populações rurais no Estado do Paraná, ver ZAFFARONI, 2001). Também não é objetivo deste trabalho discutir o desenvolvimento do geoprocessamento e de suas técnicas, como ferramenta de segurança pública, discussão essa já feita em diversos outros trabalhos específicos sobre o tema. são verdadeiras cidades dentro das cidades, ou por motivos relacionados à violência e a falta de estrutura das áreas menos favorecidas economicamente.

Com relação à violência letal observamos um contínuo aumento no número de homicídios (crime universalmente utilizado como parâmetro para delimitar a quanto uma sociedade está submetida à violência), conforme descrito por Wailselfisz (2011, p. 21):

No período que compreende os anos de 1998 e 2008, o número total de homicídios registrados pelo SIM passou de 41.950 para 50.113 , o que representa um incremento de $17,8 \%$, levemente superior ao incremento populacional do período que, segundo estimativas oficiais, foi de $17,2 \%$. (...) Já em 2004, essa tendência se reverte, quando o número de homicídios cai 5,2\% em relação a 2003. A queda - como veremos mais adiante pode ser atribuída às políticas de desarmamento desenvolvidas na época. Com menor intensidade, o declínio continua em 2004. Porém, a partir de 2005, os números absolutos começam a oscilar fortemente: elevam-se em 2006, e caem novamente em 2007 para voltar a crescer de forma acentuada em 2008. Contrastando com o perío- 
do anterior, de crescimento sistemático, os dados se revelam contraditórios, crescendo em um ano, caindo no outro. Isso indica a presença de forças também contraditórias, cuja prevalência circunstancial pressiona os quantitativos nacionais ora para cima ora para baixo. Encontramos uma primeira explicação ao focarmos a situação e evolução nas grandes regiões do país ou nas Unidades da Federação, o que nos dá um panorama bem complexo e heterogêneo.

Nesse caso observamos que a violência letal no Brasil é endêmica e, apesar das recentes quedas em alguns Estados, como Rio de Janeiro e São Paulo², as taxas nacionais ainda são elevadas. Com relação à violência no Bra-

2 Curitiba é três vezes mais violenta do que a cidade de São Paulo. De acordo com os dados oficiais apresentados pelo Mapa do Crime, divulgado pela Secretaria de Estado de Segurança Pública (Sesp), a capital paranaense - com uma população estimada em 1,8 milhão de pessoas - registrou 632 homicídios em 2009, o que representa uma taxa de 34 homicídios a cada 100 mil habitantes. A cidade de São Paulo - com 11 milhões de pessoas - atingiu 1.235 homicídios no mesmo ano, segundo o governo estadual paulista. A média da maior cidade do país é de 11 assassinatos por 100 mil habitantes. A comparação só foi possível agora que a Sesp divulgou os dados oficiais, depois da saída de Roberto Requião (PMDB) do governo. Quando os crimes da região metropolitana de Curitiba são somados aos da capital, os números são ainda mais preocupantes: foram 1.523 assassinatos em 2009 - o que, para 3,3 milhões de habitantes, resulta em 46 homicídios por 100 mil habitantes. "A taxa de Curitiba é bastante elevada em relação ao contexto nacional e demonstra uma deterioração na cidade", afirma Ignácio Cano, doutor em Sociologia e integrante do Laboratório de Análise da Violência da Universidade Federal do Rio de Janeiro (UFRJ). Disponível em: http://www.gazetadopovo.com.br/vidaecidadania/conteudo. phtml?t|=1\&id=99 8243\&tit=Curitiba-e-tres-vezes-mais-violenta-que-Sao-Paulo-E-empata-com-o-Rio. Acesso em 10/04/2011. sil, de uma forma geral, Minayo et al (2003, p. 83) afirmam que:

Nas duas últimas décadas do século $X X, 0$ crescimento da violência no Brasil vem afetando todos os setores da sociedade. Tal crescimento enseja a discussão de que o país estaria passando por uma nova epidemia social e por um dos mais graves problemas de saúde pública a ser enfrentado. Essa argumentação se fundamenta no número total e nas taxas de óbito, na quantidade, na intensidade e na variedade das formas de violência e na penetração que esse fenômeno passou a ter nos cenários da vida individual e coletiva, na deterioração da qualidade de vida e nas condições de saúde da população, particularmente nas grandes metrópoles.

O Estado do Paraná não foge à regra no que diz respeito ao contínuo aumento da criminalidade, atingindo, proporcionalmente, índices maiores que as cidades do Rio de Janeiro e São Paulo . Para buscar enfrentar os números cada vez maiores de crimes, os governos anteriores ao ano de 2003 realizaram somente o aumento dos efetivos das instituições policiais, 
compraram veículos policiais e armamento, ficando restrito ao modelo "mais do mesmo" que não fez frente aos novos desafios no que diz respeito à segurança pública nos dias atuais. Este artigo se propõe a descrever e discutir a criação do Projeto Mapa do Crime e a sua posterior transformação em um setor de análise criminal no âmbito da Secretaria de Segurança Pública do Estado do Paraná, bem como discutir os avanços e as resistências encontradas no decorrer desse processo.

\section{O início do Projeto Mapa do Crime}

Para tentar reverter o quadro problemático na segurança pública com relação ao modelo de atuação nessa área específica da administração estadual, o governador eleito para a gestão 2003/2006 propôs a criação de um grupo que iniciasse estudos no sentido de realizar um diagnóstico da estatística criminal do Estado e as necessidades para viabilizar a realização do geoprocessamento dos registros policiais, buscando melhor utilizar os recursos disponíveis e otimizar os resultados.

Em fevereiro do ano 2003, por meio da Secretaria de Estado do Planejamento e Coordenação Geral, foi instituído um projeto cujo propósito maior foi o de desenvolver uma proposta metodológica exeqüível para implantar, no âmbito da Segurança Pública Estadual, uma ferramenta para identificar, localizar e mensurar as ocorrências policiais de forma a proporcionar organização, clareza e transparência às informações geradas pelos registros policiais. Proporcionar também bases para a proposição de soluções aos problemas de criminalidade e violência que crescentemente vinham assolando o território paranaense, focando principalmente em suas maiores cidades.

Com essa diretriz o projeto que se denominou Projeto Mapa do Crime - Planejamento e Segurança - sugeriu a introdução de algumas inovações metodológicas: quanto aos re- 
gistros e gestão das informações das ocorrências policiais, com a criação de um sistema de boletim de ocorrências unificado e informatizado; quanto à unificação das áreas de abrangência de gestão geográfica das polícias civil e militar, com o objetivo de melhorar a gerência das tarefas afins; a criação de um comitê gestor como fórum de discussão das ações de segurança e pela realização de pesquisas de vitimização como forma de ampliar a visão dos problemas referentes à segurança cidadã e como meio de complementar as informações geradas pelos registros oficiais de ocorrências policiais.

Os trabalhos do grupo anteriormente citado tinham como objeto o estudo das bases cadastrais de ocorrências das Polícias Civil e Militar e o objetivo de propor uma forma concisa e cientifica para que esse conhecimento fosse aproveitado para o planejamento integrado entre as instituições policiais. Borba (2010, p. 80) assim descreve:
Em janeiro de 2003, foram realizadas diversas reuniões, sob coordenação da SEPL e com o apoio técnico de profissionais do Instituto Paranaense e Pesquisa Econômico e Social (IPARDES), em que se coletaram propostas e conheceram soluções comerciais e também no âmbito da administração pública. A SEPL constatou inicialmente a inexistência de um sistema de gestão no âmbito da SESP, que possuía apenas sistemas isolados ou participando dos sistemas estruturantes do Estado (finanças, recursos humanos/administração) na função de usuário do sistema.

Durante o processo inicial de implantação do projeto MAPA DO CRIME, foi realizada uma visita técnica em algumas cidades dos Estados Unidos da América com o objetivo de buscar soluções compatíveis e que pudessem ser adaptadas à realidade paranaense, com ênfase ao modelo do Departamento de Polícia da cidade de Nova York, denominado Compstat (Computer Statistic) (BORBA, 2010).

Como pressuposto metodológico ainda definido durante a fase de implantação do projeto MAPA DO CRIME ficou estabelecida a ne- 
cessidade de um único registro para as ocorrências policiais, quando foi criado o Boletim de Ocorrência Unificado (BOU) ${ }^{3}$, visando a meIhoria da entrada de dados das duas polícias estaduais em um único banco informatizado.

Com essa medida buscou-se diminuir a subnotificação dos registros e também possibilitar ao cidadão a oportunidade dar a "notícia crime" a qualquer uma das autoridades policiais não mais necessitando acionar a Polícia Militar e posteriormente deslocar-se a uma delegacia de Polícia Civil.

No transcorrer do ano de 2004 e 2005 foram tomadas várias medidas no intuito de 3 "O Boletim de Ocorrência Unificado é mais uma ferramenta pioneira implantada pelo Governo do Paraná para combater a criminalidade e levar mais segurança e comodidade à população. Agora, o próprio policial militar, quando faz o atendimento de ocorrências nas ruas poderá registrar o BO para que a pessoa não precise mais se dirigir à delegacia de polícia. Além de mais conforto para o cidadão, o BO Unificado garante extrema confiabilidade às estatísticas policiais colocando definitivamente um fim à duplicidade de informações já que antes de sua implantação a PM e a Polícia Civil tinham bancos de dados separados. • Esta unificação definitiva das informações sobre crimes e contravenções coloca mais uma vez o estado do Paraná à frente de outras unidades da federação. Tudo porque o Paraná é o primeiro a usar um único boletim de ocorrência desde o primeiro registro até a finalização das investigações e que futuramente irá incluir até mesmo o andamento e resultado do procedimento no Poder". Judiciário. 0 BO Unificado é essencial para a formação do banco de dados usado pelo Geoprocessamento - Mapa do Crime. Disponível em http://www.seguranca.pr.gov $\mathrm{br} /$ modules/conteudo/conteudo.php?conteudo $=17$. realizar a adoção do Boletim de Ocorrências Unificado. Estudos foram elaborados para propor a melhor forma de coleta dos dados e as informações que deveriam compor essa base cadastral. Todo o sistema - Boletim de Ocorrências Unificado - foi idealizado para constituir uma base de análise criminal, como também trazer alguns benefícios à população. Contudo, à época, entendeu-se que a estatística criminal também poderia ser produzida diretamente da mesma base de informação.

Em meados de 2005, com a filosofia do programa estabelecida, formulários confeccionados e um sistema informatizado previamente elaborado, iniciaram-se as discussões para a edição da norma destinada a colocar em vigor o BOU.

No mês de dezembro de 2005, por meio da Resolução no 309 do Secretário de Estado da Segurança Pública, foi colocado em vigor o Boletim de Ocorrência Unificado que carregava o fardo de resolver inúmeros problemas de- 
aaaa ordem administrativa e operacional das duas instituições policiais propiciados por falta de visão estratégica e anos de inércia de seus dirigentes.

Como primeiro impacto direto da inação das instituições policiais foi a inclusão de naturezas não criminais para serem controladas pelo sistema BOU, sob a alegação de que as Polícias não poderiam fazer frente à criação de um sistema para controlar essas informações de caráter administrativo e que esses dados deveriam compor a base do BOU.

À época, foram elaboradas estimativas de impacto dessa medida e quais problemas poderiam trazer ao projeto. Porém, em decorrência de imperativos políticos e não técnicos, esses possíveis problemas foram desconsiderados e o BOU abrangeu também as ocorrências não criminais.

$\mathrm{Na}$ atualidade são inúmeros os problemas enfrentados em decorrência de falhas na implantação do BOU, como por exemplo:
- A falta da ampla e exaustiva discussão da nova metodologia e dos novos formulários com todos os níveis das instituições não possibilitou a tomada do novo projeto como essencial às instituições, pelo contrário, foi visto como impositivo, burocrático e pouco prático.

- Os treinamentos efetuados foram deficitários e não atingiram todo o público que iria manipular o novo Boletim, havendo com isso inúmeras falhas de preenchimento;

- Muitos policiais ainda hoje não sabem o porquê das mudanças e a que se destinam as informações, pois não ocorreu a ampla democratização das informações;

- As instituições não colocaram como prioridade o novo sistema e com isso os seus gestores não se preocuparam com a qualidade da informação, como também não se utilizam das informações para planejar suas ações.

Outro pressuposto necessário também visto na fase inicial do projeto foi a criação de 
uma base cartográfica de arruamento das áreas urbanas do Estado do Paraná. Para tal, foi realizado um convênio com a Companhia Paranaense de Energia (COPEL) que forneceu a localização espacial (coordenadas $x$ e y) dos postes de energia, que serviu de base para a geração da base cartográfica que propiciou a realização do mapeamento das ocorrências policiais.

Até o momento, um dos problemas enfrentados pela equipe de geoprocessamento da CAPE é a falta de planos diretores na maioria das cidades paranaenses. Isso impossibilita a existência de um padrão no que diz respeito ao endereçamento e numeração e também na delimitação de bairros oficiais, ficando evidente que a dinâmica urbana com relação à delimitação de ruas e bairros é muito mais rápida e baseada nos critérios do senso comum da população local, ficando o poder público alheio a esse problema.

Como medida de imputação de respon- sabilidade foram criadas as Áreas Integradas de Segurança Pública (AISP) que, como comenta Borba (2010), as responsabilidades territoriais das duas instituições policiais foi limitada à mesma área geográfica, melhorando com isso o planejamento das ações de controle da criminalidade.

O projeto Mapa do Crime também colocou fim ao impasse da lavratura do Termo Circunstanciado de Infração Penal (TCIP) ${ }^{4}$ pela Polícia Militar. O entendimento do governo foi de que o policial militar é autoridade competente para a lavratura do TCIP, e com essa medida pretendia-se evitar o deslocamento do cidadão vítima de algum crime de menor potencial ofensivo até uma delegacia da Polícia Civil.

\footnotetext{
4 Termo Circunstanciado de Infração Penal (TCIP) é o registro feito para os crimes e contravenções penais em que a pena máxima não ultrapasse dois anos. Existia um grande entrave jurídico com relação de qual instituição teria a responsabilidade da lavratura do TCIP. O assunto "TCIP" ainda é um tema extremamente controverso para as instituições policiais no Brasil, pois a Polícia Civil entende que a lavratura desse documento é trabalho específico de polícia judiciária e não deveria ser efetuado pela polícia administrativa, porém o poder judiciário tem se manifestado pela competência da lavratura do TCIP pela Polícia Militar.
} 
Buscando realizar o geoprocessamento das ocorrências policiais, a equipe formada em 2003 realizou levantamento tabulando os dados das Polícias Civil e Militar, com intuito de verificar a existência de sobreposição de registros e quais as possibilidades de utilização dos diferentes tipos de bancos de dados para a geração de mapas georreferenciados. O relatório final demonstrou que um número considerável de ocorrências eram registradas de forma duplicada nas duas instituições policiais.

Como anteriormente relatado, a base do Boletim de Ocorrência Unificado foi idealizada para a produção da análise criminal, contudo não apresenta boa configuração para a produção da estatística, pois não possibilita a retirada direta dos valores sem que antes ocorra um amplo trabalho de depuração.

Outro problema é que os gestores raramente retornam ao BOU para corrigir naturezas desclassificadas ou até mesmo erroneamente catalogadas, contudo essas inconsistências não inviabilizam a analise e nem mesmo o planejamento focado ao problema.

O projeto Mapa do Crime, com a espacialização possível dos dados disponíveis dos maiores municípios do Estado, identificou que em torno de um terço das ocorrências policiais eram sobrepostas, ou seja, os registros eram efetuados na Polícia Militar e na Polícia Civil, demonstrando mais uma vez a necessidade de um banco de dados único para diminuir a subnotificação, facilitar o planejamento das ações policiais e a aplicação dos recursos humanos e materiais.

$\mathrm{Na}$ busca de auxiliar o projeto o governo do Estado no ano de 2005 contratou uma empresa de consultoria, com sede na Cidade de São Paulo, para que fornecesse subsídios nas fases iniciais de implementação. Uma crítica que deve ser colocada é que a referida empresa não tinha atuação específica na área de geoprocessamento e tinha como campo de atuação "pesquisas de opinião", e também no 
fornecimento de pacotes estatísticos (softwares), além de atuar na intermediação da venda de um software de mapeamento.

\section{A criação da Coordenadoria de Análise e Planejamento Estratégico CAPE/SESP PR}

Após a absorção do projeto pela Secretaria de Segurança Pública, a equipe do projeto MAPA DO CRIME foi composta por técnicos do Instituto Paranaense de Desenvolvimento Econômico e Social, policiais militares e civis, todos com alguma formação universitária vinculada com análise criminal e geoprocessamento, sendo que em Dezembro de 2005 foi criada a Coordenadoria de Análise e Planejamento Estratégico, pelo decreto estadual no 5889. Essa equipe foi responsável por colocar em funcionamento o Boletim de Ocorrência Unificado.

No ano de 2005, como resultado dessas primeiras ações do projeto MAPA DO CRIME, as 13 companhias operacionais da Polícia Militar e as 13 Delegacias da Polícia Civil ${ }^{5}$ da Ca5 Na Capital, as companhias da Policia Militar e as Delegacias Distritais da Polícia Civil possuem a mesma circunscrição territorial denominadas SubAISP's (Sub Áreas Integradas de Segurança Pública). A idéia original era que as ações das duas instituições policiais estaduais fossem planejadas de forma integrada pelas duas polícias, porém na prática, ainda as ações não possuem um bom nível de entrosamento. pital do Estado receberam mapas plotados em tamanho $A 0$ e também gravados em um $C D$, sempre em formato PDF, para que não fossem modificados e também para facilitar a visualização dos mesmos.

Esses mapas foram produzidos por software ARC VIEW 3.2, utilizando a base de arruamentos da Prefeitura Municipal de Curitiba e indicavam a distribuição de alguns tipos principais de crimes, dentre eles roubos, furtos, crimes sexuais e aqueles relativos ao tráfico, uso e ou porte de entorpecentes, sempre separados por dias da semana e faixa horária, possibilitando aos gestores das unidades policiais utilizar os recursos disponíveis de acordo com a distribuição temporal e espacial dos registros de ocorrências policiais.

Apesar de todas as unidades da Polícia Militar e também da Polícia Civil receberem os mapas plotados em papel e também gravados em uma mídia, diversos foram os problemas observados pela equipe da CAPE com relação às deficiências de infraestrutura das unidades que estão em contato diretamente com a população. Essas deficiências variavam desde falta de computadores com leitores de CD-Rom, falta de conhecimento na utilização do material fornecido e uma melhor preparação para o emprego de dados georreferenciados para o planejamento das ações de policiamento preventivo ou repressivo e também de investigação. 
Com a efetiva implementação do Boletim de Ocorrência Unificado em Janeiro de 2006, durante a Operação Verão ${ }^{6}$, um próximo passo foi dado na consecução do Sistema de Gestão de Segurança Pública. Iniciou-se um processo de acompanhamento por parte do Secretário de Segurança Pública do Estado, denominado Comitê Gestor de Segurança Pública, que consistia em uma sala para apresentação dos números sobre os registros criminais de todo o Estado do Paraná. Nessa reunião compareciam além do Secretário de Segurança, o Delegado Geral de Polícia Civil, o Comandante Geral da Polícia Militar e, dependendo da cidade ou bairro da Capital analisado, compareciam também os respectivos comandantes e delegados (Figura 1).

Durante a reunião, eram apresentadas análises espacial e temporal por meio de dados estatísticos e mapas produzidos pelos in6 O lançamento do Boletim Unificado de Ocorrência ocorreu na sede da Operação Verão, no litoral do Estado do Paraná, ficando restrito aos municípios dessa região, sendo que após foi gradativamente sendo implantado no restante do Estado.

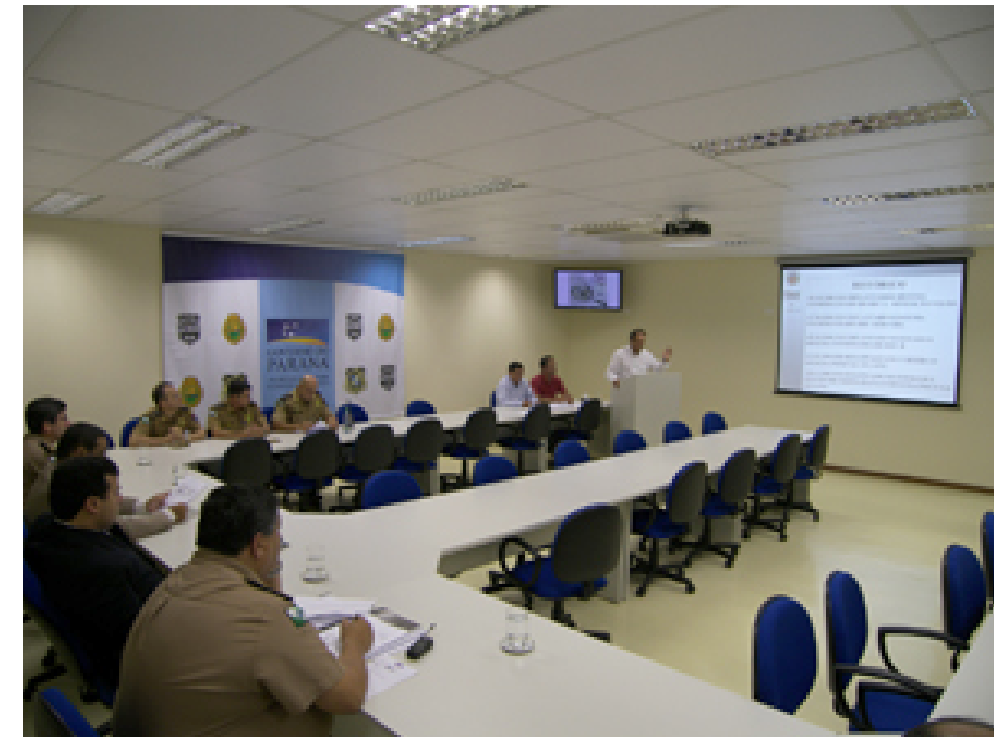

Figura 1 - Reunião do Comitê Gestor de Segurança Pública do Estado do Paraná Fonte: SESP/PR, 2010

tegrantes da CAPE (figuras 2 e 3 ) e os respectivos comandantes das áreas geográficas analisadas apresentavam as suas considerações, sugestões e também os problemas de suas unidades. Dessa forma, obtinha-se um diagnóstico da situação da segurança pública das localidades áreas avaliadas?.

7 Após as primeiras reuniões, foi definida uma agenda semestral para que todos os responsáveis pela segurança pública no estado tomassem ciência das reuniões e para que fossem efetivadas ações policiais para a redução dos principais indicadores criminais. 
COMPARATIVO TRIMESTRAL NO ANO DE 2006 DOS INDICADORES CRIMINAIS DO BAIRRO CAJURU

\begin{tabular}{|c|c|c|c|c|c|}
\hline NATUREZAS & $2^{\circ}$ TRIMES TRE & $3^{\circ}$ TRIMESTRE & TOTAL & ABSOLUTA & PERCENTUAL \\
\hline$\overline{\text { SEM ILICITUDE }}$ & 667 & 354 & 1021 & -313 & $-46,93$ \\
\hline FURTO & 176 & 138 & 314 & -38 & $-21,59$ \\
\hline ROUBO & 123 & 144 & 267 & 21 & 17,07 \\
\hline HOMICÍDIO & 17 & 8 & 25 & -9 & $-52,94$ \\
\hline LESÃO CORPORAL & 30 & 40 & 70 & 10 & 33,33 \\
\hline POSSE/PORTE DE ARMA DE FOGO & 19 & 15 & 34 & -4 & $-21,05$ \\
\hline ESTELIONATO & 13 & 8 & 21 & -5 & $-38,46$ \\
\hline TRÁFICO DE ENTORPECENTE & 9 & 2 & 11 & -7 & $-77,78$ \\
\hline USO/PORTE ENTORPECENTE & 5 & 9 & 14 & 4 & 80 \\
\hline ESTUPRO & 0 & 4 & 4 & 4 & 400 \\
\hline ATENTADO VIOL. AO PUDOR & 1 & 2 & 3 & 1 & 100 \\
\hline TOTAL DE OCORRÊNCIAS & 1253 & 879 & 2132 & -374 & $-29,85$ \\
\hline
\end{tabular}

Figura 2. Tabela utilizada em 2006, durante as primeiras avaliações do Comitê Gestor da SESP/PR, referente ao Bairro Cajuru, em Curitiba 
$\hat{\Lambda}$

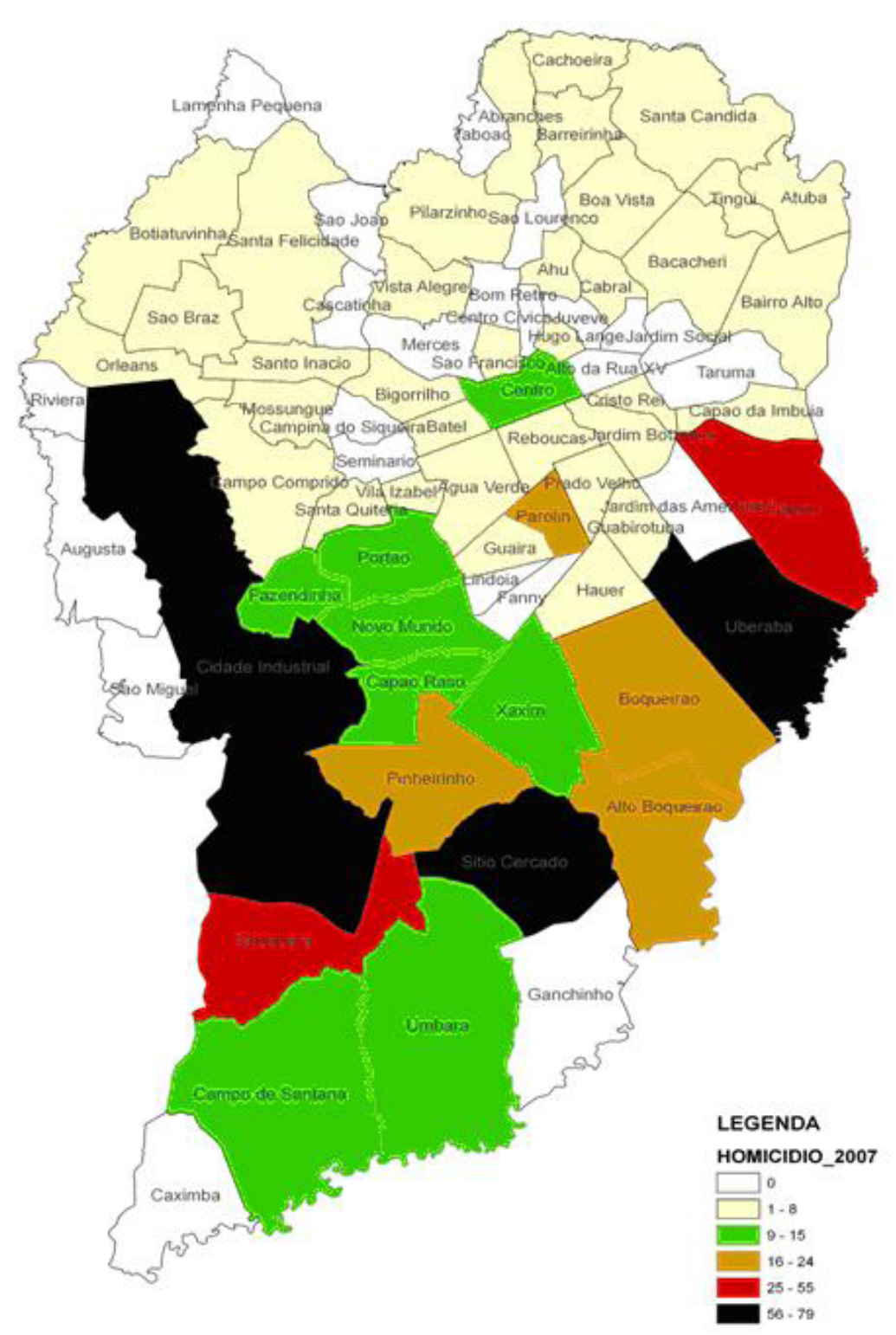

Figura 3. Mapeamento por bairros do município de Curitiba, do indicador homicídio, utilizada em 2008, durante as avaliações do Comitê Gestor da SESP/PR.

Fonte: SESP/PR, 2009

Revista Geografares, n¹0, p.156-175, Março, 2012

ISSN $2175-370$ 
Após alguns meses, iniciaram-se as reuniões de reavaliação das cidades e dos bairros da Capital que haviam sido avaliados no início, sendo que os gestores locais eram cobrados para que conseguissem reduzir alguns indicadores criminais ${ }^{8}$. Além desses indicadores, os gestores locais de segurança pública apresentavam de forma não padronizada e aleatória suas percepções e ações a respeito de suas unidades. Contudo basicamente resumiam-se a fotografias de reformas e outras questões pontuais como o número de viaturas, armamento, efetivo, e muito pouco se debatia a respeito dos reais problemas que afetavam a população local.

Após aproximadamente 250 reuniões de avaliação e reavaliação, foram treinados, em 8 Delimitaram-se como indicador criminal os registros de crimes baseados no Código Penal Brasileiro, sendo eles: Homicídio Doloso; Homicídio Culposo; Lesão Corporal; Roubo; Furto Simples; Furto Qualificado; Estelionato; Extorsão Mediante Seqüestro; Posse/Porte Ilegal de Arma de Fogo de Uso Restrito, Permitido Com ou Sem Sinal Adulterado/Suprimido; Tráfico de Entorpecentes; Uso/Porte de Substância Entorpecente; Estupro; Atentado Violento ao Pudor; Furto Roubo e Recuperação de Veículos; Receptação. Apesar desses indicadores serem essenciais para a atividade policial, e da existência de uma tentativa de padronização por parte da Secretaria Nacional de Segurança Pública (SENASP/MJ), ainda estamos longe de chegar a um consenso nacional. nível básico, aproximadamente 300 policiais civis e militares para que realizassem algumas análises estatísticas utilizando para tal a base de dados do Boletim de Ocorrência Unificado, pois, por meio da instrução normativa 001/2010, o Secretário de Estado da Segurança Pública estabeleceu a criação de reuniões do Comitê Gestor de Segurança Pública a níveis regionais.

A medida buscava uma maior democratização no acesso aos dados de registros no Boletim de Ocorrências Unificado e também um maior envolvimento dos policiais em nível local no que diz respeito ao planejamento operacional das instituições.

O maior problema enfrentado com relação a efetivação da doutrina de analise criminal é a grande rotatividade dos policiais civis e militares, fazendo com que a maioria daqueles treinados no nível básico não se encontrem mais nas áreas de planejamento de suas unidades policiais, dificultando o uso dos dados, 
uma vez que a informação é compartimentada e baseada a na produção do policial previamente treinado.

\section{Considerações Finais}

Diante do exposto, nota-se que o projeto Mapa do Crime iniciado no ano de 2003 trouxe transformações para a Segurança Pública do Estado do Paraná, pois em um prazo muito curto reformulou a dogmática do ciclo de polícia do Estado, não mais obrigando ao cidadão noticiar o fato ilícito às duas instituições.

O novo Boletim de Ocorrência Unificado proporcionou a formação de uma base de dados única para a Polícia Civil e Militar, contudo as instituições pouco participam da produção do conhecimento decorrente dessa base de informação, como também não se preocupam com a qualidade da informação, o que demanda retrabalho, consultas complementares e depurações por parte dos analistas criminais.

Paira sobre as instituições policiais a falta de maturidade para o trabalho de forma uni- ficada. Vaidades e medo do controle causam barreiras quase que intransponíveis à evolução do sistema de gestão. A falta de cultura do trabalho com indicadores e a não realização de planos estratégicos para nortear as ações futuras causam uma inércia que beira ao niilismo institucional, fenômeno visto em quase todas as instituições policiais brasileiras.

No Estado do Paraná a atividade de análise criminal e o geoprocessamento das ocorrências apresentaram grande avanço no plano estratégico, pois a cúpula das instituições e da Secretaria de Segurança Pública tem amplo acesso às informações produzido pela Coordenadoria de Análise e Planejamento Estratégico, o que não ocorre com os níveis tático e principalmente operacional ${ }^{9}$.

9 Fica evidente para os autores deste artigo que a imposição por parte da Secretaria de Segurança Pública do Paraná, para as instituições policiais estaduais (PM e PC), de um modelo de registros de ocorrências unificado e a utilização das informações para a geração de analise criminal e mapas que possibilitem o planejamento de suas atividades, não foi bem aceito, sendo ainda objeto de rejeição, seja pelos comandos, ou seja, pelos policiais envolvidos na atividade fim. A aceitação desse modelo ficou restringida a poucos profissionais em função de comando de determinadas unidades especializadas, mas que em virtude da grande rotatividade desses cargos, a continuidade desses trabalhos fica prejudicada. 
Esse fenômeno se deve ao Gestor da Secretaria do Governo anterior, que adotou a postura de trazer os problemas operacionais para dentro da Secretaria de Segurança, passando a quase comandar diretamente as atividades operacionais, e com isso, não havia a necessidade da fluidez do conhecimento produzido.

Outro aspecto negativo decorrente dessa postura foi visto durante as reuniões do Comitê Gestor de Segurança Pública, pois quando um gestor local apresentava problemas ligados à conduta operacional acabava por atacar as orientações diretas do Secretário, o que era visto de maneira negativa e de imediato refutado, causando um atuar teatral dos Oficiais Comandantes e Delegados responsáveis pelas Delegacias locais.

Com o novo governo e com fomento realizado pela CAPE, nota-se que as instituições começaram a se preocupar com a estatística, a análise criminal e o monitoramento de indicadores. A Polícia Militar levou Oficiais ligados à Coordenadoria para dentro de seus setores de planejamento e a Polícia Civil estuda a criação de uma estrutura similar a CAPE dentro de seus quadros o que demonstra que mudanças efetivas ocorreram e um caminhar evolutivo está ocorrendo.

Porém, mesmo com os avanços proporcionados pela utilização do Boletim de Ocorrência Unificado e da espacialização das informações provenientes desses documentos, as instituições policiais no Brasil em geral não apresentaram mudanças significativas em suas estruturas, mantendo um modelo extremamente engessado e com poucas possibilidades de mudanças. Essa estagnação contribuiu para que iniciativas como essa não sejam aceitas facilmente, demandando muito mais tempo para a sua assimilação, ficando o modelo de segurança pública baseado no trinômio compra de veículos policiais, armas e efetivo das instituições, não apresentando mudanças significativas na prática cotidiana dessas instituições. 


\section{Referências}

BORBA, Marcos Antônio Wosny, Segurança pública: uma análise crítica sobre o modelo de gestão do Paraná. Trabalho de Conclusão do Curso Superior de Polícia, Academia Policial Militar do Guatupê, São José dos Pinhais, 2010.

GAZETA DO POVO, edição do dia 01 de Maio de 2010. Disponível em http://www.gazetadopovo. com. br/vidaecidadania/conteudo.phtml?tl=1\&id=998243\&tit=Curitiba-e-tres-vezes-mais-violenta-que-Sao-Paulo-E-empata-com-o-Rio. Acesso em 10/04/2011.

PERES, Aline; RIBEIRO, Diego. Curitiba é três vezes mais violenta que São Paulo. E empata com o Rio. Gazeta do Povo, Curitiba, 01 mai 2010. Disponível em http://www.gazetadopovo.com.br/vidaecidadania/conteudo. phtml?tl=1\&id=998243\&tit=Curitiba-e-tres-vezes-mais-violenta-que-Sao-Paulo-E-empata-com-o-Rio. Acesso em: 10 abr 2011.

MINAYO, Maria Cecília de Souza, et al Análise Temporal da Mortalidade por Causas Externas no Brasil: Décadas de 80 e 90 in MINAYO, Maria Cecília de Souza \& SOUZA. Violência sob o Olhar da Saúde: a infrapolítica da contemporaneidade brasileira. Rio de Janeiro. Editora da FIOCRUZ, 2003.

SECRETARIA DE ESTADO DA SEGURANÇA PÚBLICA. O BO Unificado é essencial para a formação do banco de dados usado pelo Geoprocessamento - Mapa do Crime. Disponível em http://www. seguranca.pr.gov.br/modules/conteudo/conteudo.php?conteudo=17. Acesso em: 20 jun 2011. 
WAILSELFISZ, Júlio Jacobo. Mapa da Violência 2011: Os Jovens do Brasil, Instituto Sangari, São Paulo, 2011.

ZAFFARONI, Eugenio Raúl, Uma Breve Análise do Paraná, O Governo Lerner: a modernização conservadora, o autoritarismo e a corrupção endêmica. Anais do Tribunal Internacional dos Crimes Contra do Latifúndio e da Política de Violação dos Direitos Humanos no Paraná, Digitado. Curitiba, 2001. 